\title{
Fitness and Sports After Total Joint Arthroplasty
}

\author{
Michael AB Naafs* \\ Dutch Internist-Endocrinologist, Health Consultant at Naafs International Health Consultancy, Netherlands
}

Submission: July 18, 2018; Published: July 26, 2018

*Corresponding author: : Michael AB Naafs, Dutch Internist-Endocrinologist, Health Consultant at Naafs International Health Consultancy, Netherlands, Tel: +31681589079; Email: naafs.healthconsultancy@gmail.com

Abstract

In this review the possibilities of physical activity (PA) or resuming sports after total joint arthroplasty (TJA) are discussed. Despite the total number of TJAs exceeding soon 1million procedures/year in the U.S. alone, Orthopedic Societies still have no scientific based answers for younger TJA patients, regarding resuming PA and sports after any type of TJA. Research in this subject has been of an underpowered nature both in trial design as well as in interest of orthopedic surgeons in patient's needs.

Abbreviations: PA: Physical Activity; TJA: Total Joint Arthroplasty; TKA: Total Knee Arthroplasty; OA: Osteoarthritis; THA: Total Hip Arthroplasty; AHA; American Heart Association; RTS: Return to Sports

\section{Introduction}

Total joint arthroplasty (TJA) is one of the most successful treatment options for patients with painful degenerative joint disease [1]. Pain relief has historically been the primary indication for total joint replacement and there are expected and relatively predictable gains in functional activities of daily living. Worldwide, more than 500.000 total joints are implanted yearly [2], with approximately 300.000 knee replacements performed in the U.S. alone [3]. Pain relief is no longer the main goal for TJA and more and more patients also ask for surgical interventions to restore their ability to participate in various athletics [4]. Higher levels of physical activities are associated with reduced risk of metabolic disease [5-7]. Patients have higher expectations nowadays for an active lifestyle. However, defining reasonable levels of activity is difficult and depends on the type of TJA.

Little evidence is available regarding TJAs on recreational and objectively aerobic fitness. The extent of symptoms or limitations during physical activity (PA) and the long-term effects of such problems are unclear. Valid predictions of return to recreational sports or other aerobic PA cannot be made [8]. Evidence of the long -term benefits of physiotherapy guidance is also lacking [9]. Nevertheless, your orthopedic surgeon will tell you the operation went okay, and you can go for another10-15 years. In this mini-review some matters and expectations will be placed in perspective in relation to the type of TJA.

\section{Total Knee Arthroplasty (TKA)}

TKA is successful for decreasing pain and functional performance, but less is known about the influence of TKA on restoring overall physical activity [10-12]. Functional performance strongly influences quality of life and is limited by osteoarthritis (OA) and following TKA [13-15]. Paxton et al. [16] reviewed the literature concerning physical activity after TKA. Eighteen studies were published since 2002 that met their selection criteria. Several studies utilizing self-reported outcomes indicate that patients perceive themselves to be more physically active after TKA then they were before surgery. Accelerometry- based outcomes indicate that physical activity for patients after TKA remains at or below pre-surgical levels. Differences in the use of instruments, duration of follow-up and characteristics of the subjects studied all contributed to these variable results [16]. In addition, these studies failed comparison of daily physical activity with healthy controls.

Another review by Arnold et al. looked at physical activity after TKA or total hip arthroplasty (THA) [17]. Eight studies were included with a total of 373 participants (238 TKA,135 THA) were included. The best available evidence indicates negligible changes in physical activity at 6 months after TKA or THA, with limited evidence for larger changes at 1 year after surgery. In the 4 studies that reported control group data, postoperative PA levels were still considerably less than those of healthy controls. The authors concluded improved perioperative strategies to instill behavioral changes that are required to narrow the gap between patient-perceived functional improvement and actual amount taken after THA and TKA [17].

Barber-Wetsin and Noyes determined physical activity (PA) and recreational sports resumed after primary TKA, symptoms or limitations with these activities, and the effect of postoperative rehabilitation of achieving fitness and sports 
goals [8]. A systematic review of the literature from 2005-2015 was conducted using the PubMed database. There were 5179 TKAs (mean age 67,5 years) followed for a mean 4,8 years postoperatively. Marked variability was present between studies regarding the percentage of patients who resumed recreational activities (34\%-100\%), most of which were low impact. Only 2 studies used accelerometers to measure PA. These reported a low range $(0 \%-! 5,5 \%)$ of patients who met American Heart Association (AHA) guidelines. Few studies determined whether symptoms or limitations were experienced during PA. None described rehabilitation exercises or factors that would influence patients 'ability to return to recreational or fitness activities. The authors concluded there is little evidence available regarding the effect of TKA on return to recreational activities and objectively measured aerobic fitness. The extent of symptoms or limitations during PA and the long -term effects of such problems remain unclear. Valid predictions cannot be made on factors that may affect return to recreational sports or other aerobic PA after TKA [8]. Could physiotherapy guided exercise help? May be.

\section{Physiotherapy After TKA}

Rehabilitation with an emphasis on physiotherapy and exercise is widely promoted after TKA. During the hospital stay, physiotherapy targets mobilization and achievement of functional goals relating to hospital discharge. Further postdischarge physiotherapy and exercise-based interventions promote re-training and functional improvement. However, provision of these services varies in content and duration.

Arzt et al. [9] performed a systematic review and metaanalysis of physiotherapy exercise following TKA. Searches identified 18 randomized trials including 1739 patients with TKA. Interventions; compared were physiotherapy exercise and no provision, home and outpatient provision, pool and gym- based provision, walking skills and more general physiotherapy, and general physiotherapy exercise with and without balance exercises or ergometer cycling. Compared with controls receiving minimal physiotherapy, patients receiving physiotherapy exercise had improved physical function at 3-4 months (SMD-0,37;95\% CI-0,62.-0,12) and pain (SMD -0,45;95\% CI-0,85.-0,06). Benefit up to 6 months was apparent when considering only higher quality studies. There was no difference for outpatient exercise compared with home-based provision in physical function or pain outcomes. There was a shortterm benefit favouring home-based physiotherapy exercise for range of motion flexion. There were no differences in outcomes when the comparator was hydrotherapy, or when additional balancing or cycling components were included. In one study, a walking skills intervention was associated with a long-term improvement in walking performance. However, all these studies were underpowered individually and in combination [9]. Future research should target improvements to long-term function, pain and performance outcomes in appropriately powered trials. So, indeed a maybe.

\section{Recommended Sports and PA after TKA}

In a large review Witjes et al. [18] showed that return to sports (RTS) and physical activity is possible after both TKA and unicondylar knee arthroplasty (UKA), with percentages varying from $36 \%$ to $100 \%$. Participation in sports seems more likely, including higher impact types, after UKA than after TKA, although after both surgeries patients tend to return to lowerimpact types of sports. Time to RTS took 13 weeks after TKA and 12 weeks after UKA, respectively, with low-impact sports making up more than $90 \%$ of cases. However, overall study quality of the included studies was limited due to confounding factors being insufficiently taken into account in most studies.

\section{Total Hip Arthroplasty (THA)}

A marked increase in participation in four common types of recreational exercise, such as walking, cycling, cross-country skiing and swimming after THA was shown by Visuru et al. [19]. Preoperatively only $2 \%$ performed regular walking, and this increased to $55 \%$ postoperatively. Cycling increased from $7 \%$ preoperatively to $29 \%$ postoperatively, swimming from $13 \%$ preoperatively to $30 \%$ postsurgery and cross-country skiing increased from $0 \%$ to $9 \%$ postsurgery [19].

Athletic activities may pose, however, special risks to an arthroplasty patient. These include acute injuries, such as periprosthetic fractures and dislocations, as well as more incipent problems that arise from repetitive loading and wear of the joint, such as osteolysis, a leading cause of aseptic loosening. Consequently, high impact activities have, traditionally prohibited by surgeons after TJA, unlike low-impact activities, which are typically encouraged for maintenance of good health [2,4]. While general recommendations can be helpful when counseling patients regarding safe athletic participation following arthroplasty, ultimately, each case has to be evaluated on an individual basis $[4,20]$.

The most important determinant of the likelihood of sport participation after both THA and TKA is preoperative participation in the sport itself $[21,22]$. Bradbury et al. reported that no preoperatively sedentary patients took up athletics after TKA, while $65 \%$ of those, who participated in athletics preoperatively returned to athletics after TKA. The investigators also noted that participation in athletics the year before surgery was specifically predictive of a return to athletics after TKA [21].

Surgical factors may affect athletic performance. In hip arthroplasty two important surgeon-controlled factors are the type of surgical approach and the amount of soft tissue dissection. Anterolateral and direct lateral approaches require partial detachment of the abductors from the greater trochanter, which may result in temporary or permanent abductor weakness. This factor may affect athletic participation, because the abductor muscles are important in many sporting activities. On the other hand, the low rate of dislocations after anterolateral and direct lateral approaches makes these techniques an attractive option 
for THA in patients who plan to return to athletics $[22,23]$. The posterior surgical approach to the hip is less used due to earlier reports of a $4,6 \%$ risk of dislocation, but capsular repair reduced this risk to less than $1 \%$ [23-25]. However, the discussion about the various procedures is still going on. In a recent small study $(n=30)$ Petis et al. [23] found no difference in 3D measured gait analysis after THA between the various procedures 6 and 12 weeks postoperatively.

Polyethylene wear is another major concern after THA, as polyethylene spacers are used in most traditional joint arthroplasties. These materials are built to withstand large cyclical forces, but the wear rate of this plastic is related to the amount of use, which has been established by in vitro [26] and in vivo studies [27]. Therefore activities that potentially expedite the wear through increased frequency or magnitude of loading, such as high impact sports, stays a primary concern. To date, there is limited information on the specific relationship between wear and sporting activities [28].

There is a lack of empirical data to support the type of activities that are safe and feasible for patients after THA. In general low-impact activities such as swimming, bowling, stationary biking, dancing, rowing and walking were allowed. Downhill and cross-country skiing, weight lifting, iceskating and pilates were activities that were allowed with experience. There was a general consensus that raqueball/squash, jogging, contact sports, high impact aerobics, baseball/softball and snowboarding were not allowed. All 169 surgeon surveyed admitted there was no scientific base for these recommendations [4].

In 2012, Delasotta et al. [29] evaluated whether patients who underwent THA adhered to these recommended activities of the 62 patients surveyed only 2 patients said they participated in activities that were discouraged by their surgeon (jogging and squash). When the other 60 patients were asked why higherimpact activities were not resumed, the main reasons were fear $(28,6 \%)$ and physician recommendation. Pain, fatigue and lack of interest were not the primary reasons for stopping higher level activities. The impact of fear was also reported by Abe et al. [30]. Sixty-one percent of patients did not return to jogging after THA because of anxiety, while only $15 \%$ reported that pain kept them from returning. Huch et al. [31] found that $56 \%$ of 285 patients stopped participating in sports "as a precaution, to go easy on the artificial joint". So, fear of movement and patient education are important considerations in postoperative rehabilitation. Factors other than endurance and pain need to be considered when evaluating patients who wish to return to sports.

The number of THAs continues to increase and it is estimated that the annual incidence of primary and revision THA will exceed 575.000 by the year 2020 with the number of patients younger than 60 steadily increasing [32]. With the burgeoning "baby boomer" generation and older athletes, who wish to return to competitive levels of sports, understanding how sporting activity affects THA outcomes is becoming more and more important. Conversely, understanding how undergoing THA may reduce or increase an individual's likelihood of continuing sports is equally important.

In this world of social media there has been considerable press about athletes who return to sports after this invasive procedure. The list includes professional ballet dancers, worldranked tennis players and master-level golfers [33]. Some of these professional athletes have been able to return at levels of function that met or exceeded preoperative ability $[34,35]$, while other athletes have been significantly less successful [36]. British (Scottish) Andy Murray, aged 31 and two-times Wimbledon winner, had hope to play at Wimbledon again this year after THA in January 2018, but did not manage, despite high training intensity. Of greater importance, however, is how the hip responds when Murray starts up the intensity of his oncourt sessions and begins to play practice sets against other ATP-players [37].

\section{Total Shoulder Arthroplasty (TSA)}

Many patients want to return to sports following shoulder replacement surgeries, including total shoulder arthroplasty, reverse total shoulder arthroplasty and hemiarthroplasty. While activity levels after THA and TKA are somewhat defined without a scientific base, studies in the field of shoulder arthroplasty are even more limited [38]. Information about activity levels and the rate of return to sports following shoulder arthroplasty would help both patients and surgeons more accurately manage expectations [38]. TSA has been shown to be a highly effective treatment for degenerative shoulder disease, with good medium -and long -term outcomes [39-41].

The number of TSAs has risen rapidly over the last decade. Since 2004, TSA has increased by approximately 3000 cases each year in the U.S., compared with an annual increase of fewer than 400 cases each year period [41]. There is however little literature focusing on return to sports after TSA [43-45]. The largest study by Bülhoff et al. [46] examined return to sports in 154 TSA patients at an average follow-up of 6,2 years. This cohort included 105 TSA patients who had participated in sports preoperatively (group 1) and 49 TSA patients who had never sported (group 2). At the time of final follow-up 60 patients (39\%) were participating in sports, and all 60 patients were from the first group. The authors concluded that patients who had not recently participated in sports are unlikely to do so after surgery. Among patients who had participated in sports preoperatively the rate to return to sports was $57 \%$ in their cohort. Furthermore, of the 45 patients who participated preoperatively and did not resume the activity postoperatively, only $18 \%$ cited shoulder problems as the reason [46]. Other studies used a mailed self- questionnaire or are all small and underpowered [44,47-49]. Sports allowed after TSA are following therefore the recommendations discussed above [4]. 


\section{Conclusion}

It is obvious that the orthopedic society has a lot to do answering questions regarding starting or resuming physical activity (PA) or sports after TJA. The statement "everything went okay and you can go for another 10-15 years" is not enough anymore. TJA patients are getting younger and want answers to the possibilities of PA and sporting after any type of TJA and discussing this before and after surgery. Despite the number of these procedures will exceed more than 1 million/year in the U.S. alone, the Orthopedic Societies still cannot provide valid scientific based answers. Research concerning this subject has been of an underpowered nature, both in trial design as well as in interest of orthopedic surgeons in patient needs.

\section{References}

1. Healy WL, Sharma S, Schwartz B, Iorio R (2008) Athletic activity after total joint arthroplasty. J Bone Joint Surg Am 90(10): 2245-2252.

2. Kuster MS (2002) Exercise recommendations after total joint replacement: A review of the current literature and proposal of scientifically based guidelines. Sports Med 32(7): 433-445.

3. Jackson JD, Smith J, Shah JP, Wisniewski SJ, Dahm DL (2009) Golf after total knee arthroplasty: Do patients return to walking the course? Am J Sports Med 37(11): 2201-2204.

4. Swanson EA, Schmalzried IP, Dorey FJ (2009) Activity recommendations after total hip and knee arthroplasty: A survey of the American Association for Hip and Knee Surgeons. J Arthroplasty 24(6): 120-126.

5. Karvonen Guiterrez CA, Sowes MR, Heeringa SG (2012) Sex dimorphism in the association of cardiometabolic characteristics and osteophytesdefined radiographic knee osteoarthritis among obese and non-obese adults NHANES 3. Osteoarthritis Cartilage 20(7): 614-621.

6. Swartz AM, Strath SJ, Bassett DR, Moore JB, Redwine BA, et al. (2003) Increasing daily walking improves glucose tolerance in overweight women. Prev Med 37(4): 356-362.

7. Liu SH, Waring ME, Eaton CB, Lapane KL (2015) Association of objectively measured physical activity and metabolic syndrome among US adults with osteoarthritis. Arthritis Care Res (Hoboken) 67(10): 1371-1378.

8. Barber-Westin SD, Noyes FR (2016) Aerobic physical fitness and recreational sports participation after total knee arthroplasty: A systematic review. Sports Health 8(6): 553-560.

9. Artz N, Elvers KT, Lowe CM, Sackley C, Jepson P, etal. (2015) Effectiveness of physiotherapy exercise following total knee replacement: Systematic review and meta-analysis. BMC Musculoskeletal Disord 16: 15.

10. Bourne RB, Chesworth BM, Davis AM, Mahomed NN, Charron KD (2010) Patient satisfaction after total knee arthroplasty: Who is satisfied and who is not? Clin Orthop Relat Res 468(1): 57-63.

11. Rosenberg M, Nierenberg G, Lenger R, Soudry M (2007) Walking ability following knee arthroplasty: A prospective pilot study of factors affecting the maximal walking distance in 18 patients before and 6 months after total knee arthroplasty. Knee 14(6): 489-492.

12. Singh JA, Lewallen DG (2014) Patient-level improvements in pain and activities of daily living after total knee arthroplasty. Rheumatology (Oxf) 53(2): 313-320.

13. Ostir GV, Berges IM, Smith PM, Smith D, Rice JL, et al. (2006) Does change in functional performance affect quality of life in persons with orthopedic impairment. Soc Indic Res 77(1): 79-93.
14. Salaffi F, Crotti M, Staucati A, Grassi W (2005) Health-related quality of life in older adults with symptomatic hip and knee osteoarthritis: A comparison with matched healthy control. Aging Clin Ex Res 17(4): 255-263.

15. Yoshida Y, Mizner RL, Ramsey DK, Mackler LS (2008) Examining outcomes from total knee arthroplasty and the relationship between quadriceps strength and knee function over time. Clin Biomech 23(3): 320-328.

16. Paxton RJ, Melanson EL, Stevens-Lapsley JE, Christiansen CL (2015) Physical activity after total knee arthroplasty: A critical review. World J Orthop 6(8): 614-622.

17. Arnold JB, Walters JL, Ferrar KE (2016) Does physical activity increase after total hip or knee arthroplasty for osteoarthritis? A systematic review. J Orthop Sports Phys Ther 49(6): 431-442.

18. Witjes S, Gouttebarge V, Kuyer PP, Van Geenen RC, Poolman RW, et al. (2016) Return to sports and physical activity after total and unicondylar knee arhroplasty: A systematic review and meta-analysis. Sports Med 46(2): 269-292.

19. Visuri T, Honkanen R (1980) Total hip replacement: Its influence on spontaneous recreation exercise habits. Arch Phys Med Rehabilit 61(7): 325-328.

20. Golant A, Christoforou DC, Slover JD, Zuckerman JD (2010) Athletic participation after hip and knee arthroplasty. Bull NYU Hosp Jt Dis 68(2): 76-83.

21. Bradbury N, Borton D, Spoo G, Cross MJ (1998) Participation in sports after total knee replacement. Am J Sports Med 26(4): 530-535.

22. Mata JM, Shahrdar C, Ferguson T (2005) Single-incision anterior approach for total hip arthroplasty on an orthopedic table. Clin Orthop Relat Res 441: 115-124.

23. Petis S, Howard J, Lanting B, Jones I, Birmingham T, et al. (2018) Comparing the anterior, posterior and lateral approach: gait analysis in total hip arthroplasty. Can J Surg 61(1): 50-57.

24. Pellicci PM, Bostrom M, Poss R (1998) Posterior approach to total hip replacement using enhanced posterior soft tissue repair. Clin Orthop Relat Res 355: 224-228.

25. White RE, Forness TJ, Alman JK, Junick DW (2001) Effect of posterior capsular repair on early dislocation in primary total hip replacement. Clin Orthop Relat Res 393: 163-167.

26. Harsha AP, Joyce TJ (2013) Comparitive wear tests of ultra-high molecular weight polyethylene and cross-linked polyethylene. Proc Inst Mech Eng H 227(5): 600-608.

27. Schmalzried TP, Shepherd EF, Dorey PJ, Jackson WO, Rosa DM, et al. (2000) The john charnley award. Wear is a function of use, not time. Clin Orthop Relat Res 381: 36-46.

28. Meira EP, Zeni J (2014) Sports participation following total hip arthroplasty. Int J Sports Phys Ther 9(6): 839-850.

29. Delasotta LA, Rangavajjula AV, Porat MD, Frank ML, Orozco FR, et al. (2012) What are young patients doing after hip reconstruction? J Arthroplasty 27(8): 1518-1525.

30. Abe H, Sakai T, Nishii T, Takao M, Nakamura N, et al. (2014) Jogging after total hip arthroplasty. Am J Sports Med 42(1): 131-137.

31. Huch K, Muller K, Sturmer T, Brenner H, Puhl W, et al. (2005) Sports activities 5 years after total knee or hip arthroplasty: The Ulm Osteoarthritis Study. Ann Rheum Dis 64(12): 1715-1720.

32. Kurtz SM, Ong KL, Lau E, Bozic KJ (2014) Impact of the economic downturn on total joint replacement demand in the United States: updated projections to 2021. J Bone Joint Surg Am 96(8): 624-630. 
33. Clfford PE, Mallon WJ (2005) Sports after total joint replacement. Cln Sports Med 24(1): 175-86.

34. Grant E (2014) Breakthrough surgery gives Ranger pitcher "ultimate stoic" Colby Lewis another chance. Dallas Mornng News-Sport DFW.

35. Custance C (2014) Ed Jovunouski really man of steel. ESPN Mag.

36. Nightengale B (2010) Bo Jackson reflects on past life 21 years after his All-Star blast. USA Today.

37. Fuller R (2018) Andy Murray delays comeback but still has Wimbledon hopes. BBC Sports.

38. Johnson CC, Johnson DJ, Liu JN, Dines JS, Dines DM, et al. (2016) Return to sports after shoulder arthroplasty. World J Orthop 7(9): 519-526.

39. Deshmukh AV, Koris M, Zurakowski D, Thornhill TS (2005) Total shoulder arthroplasty: Long term survivorship, functional outcome, and quality of life. J Shoulder Elbow Surg 14(5): 471-479.

40. Torchia ME, Cofield RH, Setteigren CR (1997) Total shoulder arthroplasty with the Neer prosthesis: Long-term results. J Shoulder Elbow Surg 6(6): 495-505.

41. Montoya F, Magosch P, Scheiderer, Lichtenberg S, Melean P, et al. (2013) Midterm results of a total shoulder prosthesis fixed with a cementless glenoid component. J Shoulder Elbow Surg 22(5): 628-635.
42. Kim SH, Wise BL, Zhang Y, Szabo RM (2011) Increasing incidence of shoulder arthroplasty in the United States. J Bone Joint Surg Am 93(24): 2294-2254.

43. Khair MM, Dines JS, Dines DM (2015) Shoulder arthroplasty: Return to sports. Sports Health S 7(1): 87-89.

44. Jensen KL, Rockwood CA (1998) Shoulder arthroplasty in recreational golfers. J Shoulder Elbow Surg 7(4): 362-367.

45. McCarthy EC, Marx RG, Maerz D, Altchek D, Warren RF, et al. (2008) Sports participation after shoulder replacement surgery. Am J Sports Med 36(8): 1577-1581.

46. Bulhoff M, Sattler P, Bruckner T, Loew M, Zeifang F, et al. (2015) Do patients return to sports and work after total shoulder replacement surgery? Am J Sports Med 43(2): 423-427.

47.Zarkadas PC, Throckmorton TQ, Dahm DL, Sperling J, Schleck CD, et al. (2011) Patient reported activities after shoulder replacement: Total and hemiarthroplasty. J Shoulder Elbow Surg 20(2): 273-280.

48. Wiethoff SR, Wolf P, Lehmann M, Habermeyer P (2002) Physical activity after shoulder arthroplasty. Sportverletz Sportschaden 16(1): 26-30.

49. Schumann K, Flury MP, Schwyzer HK, Simmen BR, Drerup S, et al (2010) Sports activity after anatomical total shoulder arthroplasty. Am J Sports Med 38(10): 2097-2105.

\section{Your next submission with Juniper Publishers will reach you the below assets}

- Quality Editorial service

- Swift Peer Review

- Reprints availability

- E-prints Service

- Manuscript Podcast for convenient understanding

- Global attainment for your research

- Manuscript accessibility in different formats ( Pdf, E-pub, Full Text, Audio)

- Unceasing customer service

Track the below URL for one-step submission https://juniperpublishers.com/online-submission.php 